\title{
The Clinopathological Profile of Pediatric Patients with Pancytopenia In Vadodara
}

\author{
Disha Singla ${ }^{1}$, Gunvanti Rathod ${ }^{2 *}$ \\ ${ }^{1}$ Consultant Pathologist, Delhi Heart Hospital, Bathinda, Panjab, India \\ ${ }^{2}$ Department of Pathology, GMERS Medical College, Valsad, Gujarat, India
}

\begin{abstract}
Introduction: Pancytopenia is a key clinico-hematological thing comes across in day-to-day medical practice. It is a situationdealing withdecreaseinred blood cells (RBCs), white blood cells (WBCs) and platelets and usually suspected medicallywith finding ofunsolved pallor. Careful check-up of a blood is important if cause for the pancytopenia does not seem from the medical history. If blood examination will not reveal cause then bone marrow aspiration and trephine are of use.

Materials and Methods: Present study was retrospective in nature and was carried out at Dhiraj General Hospital, Sumandeep Vidyapeeth, Vadodara from January 2014 to December 2015 for period of 2 years. All pediatric patients who came to hospital were became part of present study and undergone necessary investigations likecomplete blood count (CBC), peripheral smear (PS) examination, bone marrow aspiration and bone marrow trephine biopsy for all subjects.

Results: Among 200 pediatric patients, most common age group was ranged from 1 month to 6 years. Megaloblastic anemia (29\%) followed by Aplastic anemia (15.0\%) found to bereason for pancytopenia whereas $21.5 \%$ of pediatric patients showedleukemiaas a reason for pancytopenia. Pallor was found to be most common symptoms in about $170(85 \%)$ patients and fever was in $123(61.5 \%)$ patients.
\end{abstract}

Conclusion: Megaloblastic anemia followed by acute leukemia and aplastic anemiaareroutine causesencountered for pancytopenia in our study.

Keywords: Pediatric Patients, Pancytopenia, Analysis, Clinopathological, Vadodara, Tertiary Care Hospital.

\section{Introduction}

Routine medical practice shows pancytopenia as frequent clinico-haematological entity. Pancytopenia is a situation where there is a decrease in red blood cells (RBCs), white blood cells (WBCs) and platelets and suspected on medical grounds where unexplained pallor for long time. Leukopenia is an unusual cause of early exhibition if remain undiagnosed then usually turned out to be fatal ${ }^{[1]}$. Anemia leads to dyspnea, fatigue, and cardiac symptoms. Thrombocytopenia often resulted in contusion, bleeding from mucosa and neutropenia which in turn lead to infection ${ }^{[2]}$. Pancytopenia is not considered as a disease entity but triangle of results which commonly occurring from anticancer chemotherapy, HIV infection, bone marrow infiltration or failure. Careful checkup of blood is significant and required when reason for the pancytopenia does not seem to be solved from the medical history. On clinical examination, the patients of pancytopenia can appear with various symptoms like pallor, fever, serious illness various infections, and death. Bone marrow aspiration and trephine biopsy is desirable to reach the conclusion, if peripheral blood examinations are not capable to disclose the reason for pancytopenia ${ }^{[3,4]}$. Identification of suitable cause for pancytopenia is vital as the original pathology regulates the future outcome of the patient in form of treatment as well as prognosis point of view. In the current study, we had tried to evaluate etiology of pancytopenia and medical grounds in pediatric patients of pancytopenia at tertiary care hospital of Vadodara. Our data would be helpful in planning the diagnostic and therapeutic approach in paediatric patients presenting with pancytopenia.

\section{Materials and Methods}

Present study was retrospective in nature and was carried out at Dhiraj General Hospital, Sumandeep Vidyapeeth, Vadodara from January, 2014 to December, 2015 after obtaining Ethical approval from Institutional Ethical Committee. Pediatric patients of age group ranging from 6 months to 14 years who were admitted with pancytopenia were included in current study. Detailed history of all pediatric patients was taken and physical examination of each patient was carried out in the OPD (outdoor patient department) in the hospital followed by collection of $2 \mathrm{ml}$ of EDTA (ethylene diamine tetraacetic acid) anticoagulated blood. The collected blood was processed through automated hematology analyzer; and various hematological parameters were obtained, which included hemoglobin, red blood cell count, total leukocyte count, differential leukocyte count, platelet count, mean corpuscular volume 
(MCV), mean corpuscular hemoglobin (MCH), mean corpuscular hemoglobin concentration (MCHC), packed cell volume (PCV).

We had selected case of pancytopenia on the bases of clinical features and laboratory evidence, which included peripheral blood counts for hemoglobin, leukocytes and platelets. Pancytopenia was considered when presence of all 3 of the following: hemoglobin was less than $9 \mathrm{~g} \%$, total leukocyte count (TLC), less than $4,000 / \mu \mathrm{L}$; platelet count less than $100,000 / \mu \mathrm{L}^{[5]}$. Erythrocyte sedimentation rate (ESR) was estimated in all cases by Westergren's method. Peripheral smear was stained by Leishman stain for all the cases and examined in detail. Other investigations in the form of reticulocyte counts, bone marrow examination were carried out to confirm the diagnosis and to analyse for the purpose of current study.

\section{Results}

Out of total 8909 patients hospitalized in Department of Pediatrics, Dhiraj General Hospital, Sumandeep Vidyapeeth, Vadodara; only 200 pediatric patients showed pancytopenia. Out of study population of 200 pediatric patients with pancytopenia, total $128(64 \%)$ were males and rest $72(36 \%)$ were females. In our study male paediatric patients were more as compared to females and Male to female ratio was found to be $1.78: 1$ as per Table -1 . Current study showed age range of patients was from 1 month to 14 years. Total 95 (47.5\%) patients were in the age group of 1 month to 6 years which was utmost common, followed by $63(31.5 \%)$ patients in the 6 to 10 years age group while $42(21 \%)$ patients were more than 11 years of age as per Table $-\mathbf{1}$.

Table - 2 shows causative pattern of 200 pediatric patients. Megaloblastic anemia was found to be the most common reason of pancytopenia present in about 58 (29\%) pediatric patients in this research, followed by leukemia in $43(21.5 \%)$ pediatric patients while Aplastic anemia was found in $30(15.0 \%)$ pediatric patients. Other reasons like iron deficiency anemia was found in 15 (7.5\%) pediatric patients, idiopathic thrombocytopenic purpura (ITP) was found in $25(12.5 \%)$ pediatric patients, anemia of chronic disorder was present in $4(2 \%)$ pediatric patients, Visceral leishmaniasis was found in $4(2 \%)$ pediatric patients, and malaria was present in $8(4.0 \%)$ pediatric patients as per Table - 2. As the present study was carried out at tertiary care hospital, Aplastic anemia is the third most common cause as these patient usually referred from peripheral centres to our hospital. No familial disease was observed in association with pancytopenia.

Presenting complaints and physical findings are as per Table - 3. Pallor was the most common symptoms present in $170(85.0 \%)$ patients and fever in $123(61.5 \%)$ patients which was frequently continued for weeks, other symptoms were contusions, hematuria, malena, bleeding form nose, petechial hemorrhages, and joint pains as per Table $\mathbf{- 3}$. . The manifestations of bleeding amongst megaloblastic anemia group, leukemia and aplastic anemia groups were quite higher than in the other causes.

Table - 1: Distribution of pediatric patients as per Age and Gender $(n=200)$.

\begin{tabular}{|c|c|c|c|}
\hline Age & Male $(\mathbf{n}=\mathbf{1 2 8})$ & Female $(\mathbf{n = 7 2})$ & Total $(\mathbf{n}=\mathbf{2 0 0})$ \\
\hline 1 month -6 years & 64 & 31 & $95(47.5 \%)$ \\
\hline 7 years -10 years & 38 & 25 & $63(31.5 \%)$ \\
\hline 11 years -14 years & 26 & 16 & $42(21 \%)$ \\
\hline Total & $\mathbf{1 2 8}$ & $\mathbf{7 2}$ & $\mathbf{2 0 0}$ \\
\hline
\end{tabular}

Table - 2: Etiological pattern of Pancytopenia at presentation in pediatric patients $(n=200)$.

\begin{tabular}{|c|c|c|}
\hline Etiology of Pancytopenia & No. of cases $(\mathbf{n}=\mathbf{2 0 0})$ & 29 \\
\hline Megaloblastic anemia & 58 & 21.5 \\
\hline Leukemia & 43 & 15 \\
\hline Aplastic anemia & 30 & 12.5 \\
\hline ITP (Idiopathic Thrombocytopenic purpura) & 25 & 7.5 \\
\hline Iron deficiency anemia & 15 & 4 \\
\hline Malaria & 08 & 3.5 \\
\hline Hemolytic anemia & 07 & 3 \\
\hline Hypersplenism & 06 & 2 \\
\hline Anemia of chronic disorder & 04 & 2 \\
\hline
\end{tabular}


Table - 3: Clinical features of pancytopenia at presentation in pediatric patients $(n=200)$.

\begin{tabular}{|c|c|c|}
\hline Clinical Feature & No. of cases & Percentage \\
\hline Pallor & 170 & 85 \\
\hline Fever & 123 & 61.5 \\
\hline Contusions & 118 & 59 \\
\hline Joint/ leg pain & 59 & 29.5 \\
\hline Gum bleeding & 56 & 28 \\
\hline Bleeding from nose & 50 & 25 \\
\hline Petechial hemorrhage & 50 & 25 \\
\hline Malena & 35 & 17.5 \\
\hline Hematuria & 35 & 17.5 \\
\hline Vomiting of blood & 17 & 8.5 \\
\hline
\end{tabular}

\section{Discussion}

Decrease in all three blood elements - erythrocytes, leucocytes and platelets is known as pancytopenia. It is not considered as a disease entity truly but a triangle of results that may occur from various disease processes. It is frequently because decrease in hematopoietic cell manufacture in the bone marrow following from infections, toxins, malignant cell infiltration, chemotherapies, and radiation ${ }^{[6]}$. The way pancytopenia presents usually raised question for option of either a bone marrow failure syndrome or acute malignancy chiefly when allied with lymphadenopathy or organomegaly. Frequently a protected prognosis is given in such situation to the relatives when keenly probed by them for the conclusion of the blood checks. Several published studies were failed to sightsee the original etiology of pancytopenia on the base of complete hemogram and bone marrow morphology, we anticipated to assess the demographic, nutritional, and age patterns of the patients with pancytopenia and cultivate method to the finding of this disorder in our patient population.

In current study, male predominance was more compared to female in all the age group which in turn showed male to female ratio as 1.78:1 which was in alliance with other studies ${ }^{[7,8]}$. It was found in this study that many disease entities other than malignancies, aplastic anemia and anemia of chronic disorder present as pancytopenia in pediatric patients. Importantly megaloblastic anemia and infections have also appeared as familiar reasons of variable degrees of cytopenias. Megaloblastic anemia due to B12 or folic acid deficiency is currently a well-recognised and conventional cause of cytopenias ${ }^{[9]}$. It can either present as bicytopenia or pancytopenia. Various studies counting all age groups have testified pancytopenia in megaloblastic anemia fluctuating from 11-47 per cent ${ }^{[9-12]}$. Megaloblastic anemia was occurred to be common (29\%) purpose for pancytopenia in the current study. Ineffective erythropoiesis, leukopoiesis and thrombopoiesis resulting due to enhanced programmed cell demise in absence of vitamin B12 or folic acid and decreased existence of precursors in peripheral blood are utmost frequently involved in causing pancytopenia in megaloblastic anemia $[13,14]$.

Bleeding exhibitions in megaloblastic anemia was found in about $42.5 \%$ of patients in current study in contrast to $20 \%$ by Khair, et al. ${ }^{[15]}$ and $3 \%$ by Chandra, et al. ${ }^{[9]}$. Malignancies like acute lymphoblastic leukemia (ALL) and aplastic anemia are auxiliary common and hazardous reasons for pancytopenia. In our study, aplastic anemia was found in $15 \%$ of patients while malignancies were found in $21.5 \%$ of pediatric patients in contrast to $20 \%$ and $21 \%$ as per Bhatnagar, et al. ${ }^{[16]}$. It is imperative to check megaloblastic anemia picture or dimorphic anaemia picture on bone marrow investigation. This rule out aplastic anemia and leukemic transformation and are more yield full than Vitamin B12 and folate level.

Malaria was causative for pancytopenia in $8(4 \%)$ cases. There were 4 cases of Plasmodium falciparum and 4 cases of Plasmodium vivax. Malaria causes anemia and thrombocytopenia due to straight incursion by parasite, immune hemolysis, disseminated intravascular coagulation hypersplenism and hemophagocytosis ${ }^{[11-22]}$. The leucopenia is infrequent.

Total 4 patients of pancytopenia showed reason of pancytopenia as Kala azar. Distended spleen resulting in hypersplenism was leading to pancytopenia in few patients ${ }^{[23]}$. Total $85 \%$ of the pediatric patients showed pallor as the commonest medical finding in current study and was in alliance with Memon, et al. ${ }^{[14]}$, Khodke, et al. ${ }^{[24]}$ and Rathod GB, et al. ${ }^{[25]}$. 


\section{Conclusion}

Pancytopenia is common in pediatric patients and routinely encountered. Examination of peripheral blood film and bone marrow biopsy were vital approach to reach the diagnosis. In current study, out of various reasons, megaloblastic anemia was established to be the routine reason for pancytopenia. Pediatric patients may show severe bleeding from various orifice and organomegaly with pancytopenia simulating conditions like acute leukemias and aplastic anemia should not be forgotten. Severe pancytopenia has noteworthy relativity with clinical outcome and can be used for indicator of prognosis.

\section{References}

1. Saxena R, Pati HP, Mahapatra M. De Gruchy's Clinical Hematology in Medical Practice. 6th Adapted Edition, London: Blackwell Science; 2013, p. 106-19.

2. Khunger JM, Arulselvi S, Sharma U, Ranga S, Talib VH. Pancytopenia - A clinico haematological study of 200 cases. Indian J Pathol Microbiol., 2002; 45: 375-9.

3. Lewis SM, Bain BJ, Bates I, Dacie JV. Dacie and Lewis Practical Haematology. Philadelphia: Churchill Livingstone/ Elsevier; 2006, p. 615.

4. Manzoor F, Karandikar MN, Nimbargi RC. Pancytopenia: A clinicohematological study. Med J Dr. D.Y. Patil Univ., 2014; 7: 27.

5. Kumar R, Kalra SP, Kumar H, Anand AC, Madan M. Pancytopenia-A six year study. J Assoc Physicians India, 2001; 49: 1079-81.

6. Savage DG, Allen RH, Gangaidzo IT, Levy LM, Gwanzura C, Moyo A, et al. Pancytopenia in Zimbabwe. Am J Med Sci., 1999; 317: 22-32.

7. Ameileena C, Vipan C, Anubhava P, Harish C. Clinicoaetiological profile of pancytopenia in pediatric practice. JIACM, 2012; 13(4): 282-5.

8. Goel RG, Bhan MK, Azany S. A study of severe anemia in hospitalized children in Afghanistan. Indian Pediatr., 1981; 18: 643-646.

9. Chandra J, Jain V, Narayan S, Sharma S, Singh V,Kapoor AK, Batra S. Folate \& cobalamin deficiency in megaloblastic anemia in children. Indian Pediatr., 2002; 39: 453-57.

10. Gomber S, Kela K, Dhingra N. Clinico-hematologicalprofile of megaloblastic anemia. Indian Pediatr., 1998; 35: 55-58.
11. Sarode R, Garewal G, Marwaha N, Marwaha RK, Varma S, Mohanty D, Das KC. Trop Geogr Med., 1989; 41: 331-36.

12. Mukhbi JM, Makumbi FA, Gwanzura C. Megaloblastic anemia in Zimbabwe: Spectrum of clinical \& hematologic manifestations. East Afr Med J, 1992; 69: 83-7.

13. Whitehead MV, Rosenblatt DS, Cooper BA. Megaloblastic Anemia. In: Nathan DG and Orkin SH. (eds), Nathan And Oski's Hematology of Infancy and Childhood. 5th edition, WB Saunders, Philadelphia, 1989; 385-422

14. Memon S, Shaikh S, Nizamani MA. Etiological spectrum of pancytopenia based on bone marrow examination in children. J Coll Physicians Surg Pak., 2008; 18: 163-7.

15. Khair SR, Kaddu S, Visalakshi S, Rao AM. Bleeding manifestations in megaloblastic anemia. Indian Pediatr., 1975; 12: 171-3.

16. Bhatnagar SK, Chandra J, Narayan S, et al. Pancytopenia in children: Etiological profile. J of Trop Pediatr., 2005; 51: 236-9.

17. Jaroonvesama NV. Intravascular coagulation in falciparum malaria. Lancet, 1972; 1: 221-23.

18. World Health Organisation Malaria Action Programme. Severe and complicated malaria. Trans Roy Soc Trop Med Hyg., 1986; 80: 185-88.

19. Perrin LH, Mackey LJ, Miescher PA. The hematology of malaria in man. Semin Hematol., 1982; 19: 70-82.

20. Hemophagocytic syndrome induced by Plasmodium falciparum malaria infection. Int J Hematol., 1996; 64: 263-66.

21. Jaff MS, Mckenna D, McCann SR. Platelet phagocytosis: a probable mechanism of thrombocytopenia in Plasmodium falciparum infection. J Clin Pathol., 1985; 38: 1318-19.

22. Abdalla S, Weatherall DJ, Wickramasinghe SN, Hughes M. The anemia of P. Falciparum malaria. Br J Hematol., 1980; 46: 171-83.

23. Chandra J, Anand V, Patwari AK, Mandal RN, Aneja S, Sharma D. Kala-azar: Experience from non endemic area in India. J Trop Pediatr., 1995; 41: 298-300.

24. Khodke K, Mariah S, Buxi G, Yadav RB, Chaturvedi NK. Bone marrow examination in cases of pancytopenia. J Indian Acad Clin Med., 2001; 2: 55-9.

25. Rathod GB, Alwani M, Patel H, Jain A. Clinicohematological analysis of Pancytopenia in Pediatric patients of tertiary care hospital. IAIM, 2015; 2(11): 15-19.

*Corresponding author:

Dr. Gunvanti Rathod, Associate Professor, Department of Pathology, GMERS Medical College, Halar Road, Nanakwada, Valsad - 396001. Gujarat, India Phone: +91 8141905206

Email: neempath@gmail.com

Financial or other Competing Interests: None. 